\title{
Voltage Source Inverter Controlled Induction Motor Drive
}

\author{
Chethan N G ${ }^{1}$, Mrs. Raksha Adappa ${ }^{2}$ \\ PG Scholar, Electrical, NMAMIT, Nitte, India ${ }^{1}$ \\ Assistant Professor, Electrical, NMAMIT, Nitte, India ${ }^{2}$
}

\begin{abstract}
Pulse width modulation based variable speed drives are widely used in industrial applications. Recent development in power electronics and semiconductor have lead to improvements in power electronic systems. A number of pulse width modulation (PWM) schemes are available to vary the voltage and supply frequency of the machine in order to vary the speed of induction machine. This paper presents a three phase voltage source inverter to control the speed of an induction machine. By varying the stator terminal voltage from voltage source inverter speed control can be achieved. Simulation results are obtained using MATLAB/SIMULINK environment for the effectiveness of the study.
\end{abstract}

Keywords: Induction Motor, PWM, Voltage source Inverter, Speed Control.

\section{INTRODUCTION}

The System employed for the motion control is called a drive, if such system makes use of electrical motors then it is known as electrical drives. In electrical drives, use of various sensors and control algorithms are done to control the speed of the motor using suitable speed control methods. The basic block diagram of an electrical drive is shown below in Fig 1:

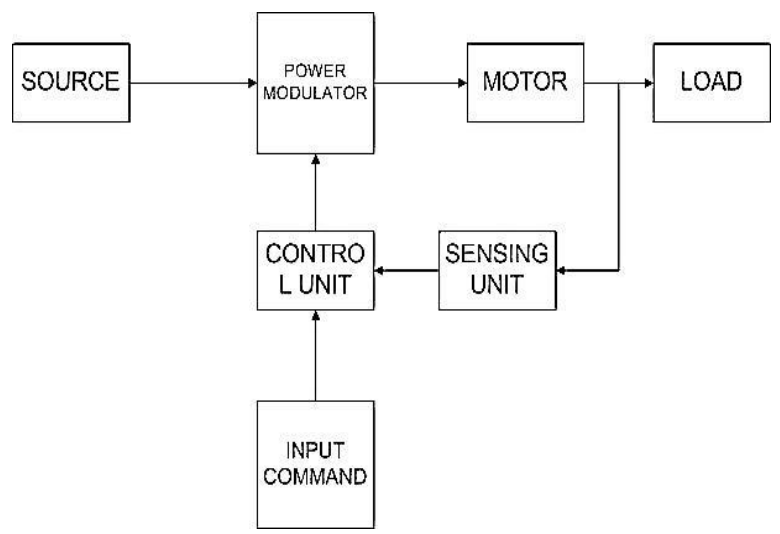

Fig 1 Block diagram of Electrical Drive

Modern trends and development in the area of speed control methods of an induction motor have increased the use of induction motors in electrical drives extensively. By the Torque-Speed characteristics, we can analyze the induction motor. In this simulation, the PI controller is employedin the system to get desired speed range and also to gain dynamic stability to the system.

A variety of speed control techniques are available for the induction motor speed control.
In this paper variable supply voltage control method is chosen due to its less complexity and cost-effectiveness. Desired speed range can be achieved by employing PI controller for the closed loop control. In the simulation studies, only PI controller is employed which gives a fast response as well as dynamic stability to the system

\section{PROPOSED SYSTEM}

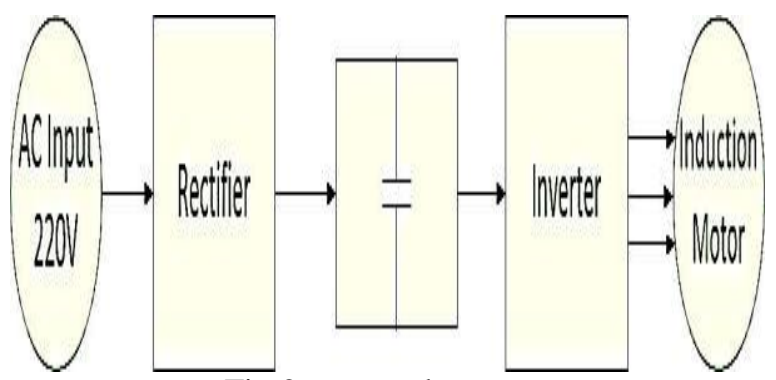

Fig 2 proposed system.

In the proposed system single phase $220 \mathrm{~V}, 50 \mathrm{~Hz}$ supply is used, which can be rectified into dc by using a diode full bridge rectifier. The output of the diode bridge rectifier contains large amount of ripples. In order to remove ripple, a capacitor filter is used here.

This ripple free dc is now provided as input to the voltage source inverter. Voltage source inverter is operated here in 180-degree conduction mode. The output of the voltage source inverter is three stepped waveforms of sinusoidal waves and of 120-degree phase shift with each other, which is provided as input to the three phase induction motor. The proposed system is shown in Fig2. 


\section{A. VSI OPERATION}

Voltage source inverter is operated in 180 degree conduction mode here, . Each switch is operated for 180 degrees. No two switches in the same leg are operated simultaneously. At any time instant three switches are on in this mode. The gating signals and the resulting line voltages for stepped wave inverter in 180 degree conduction mode are shown in Figure 3.

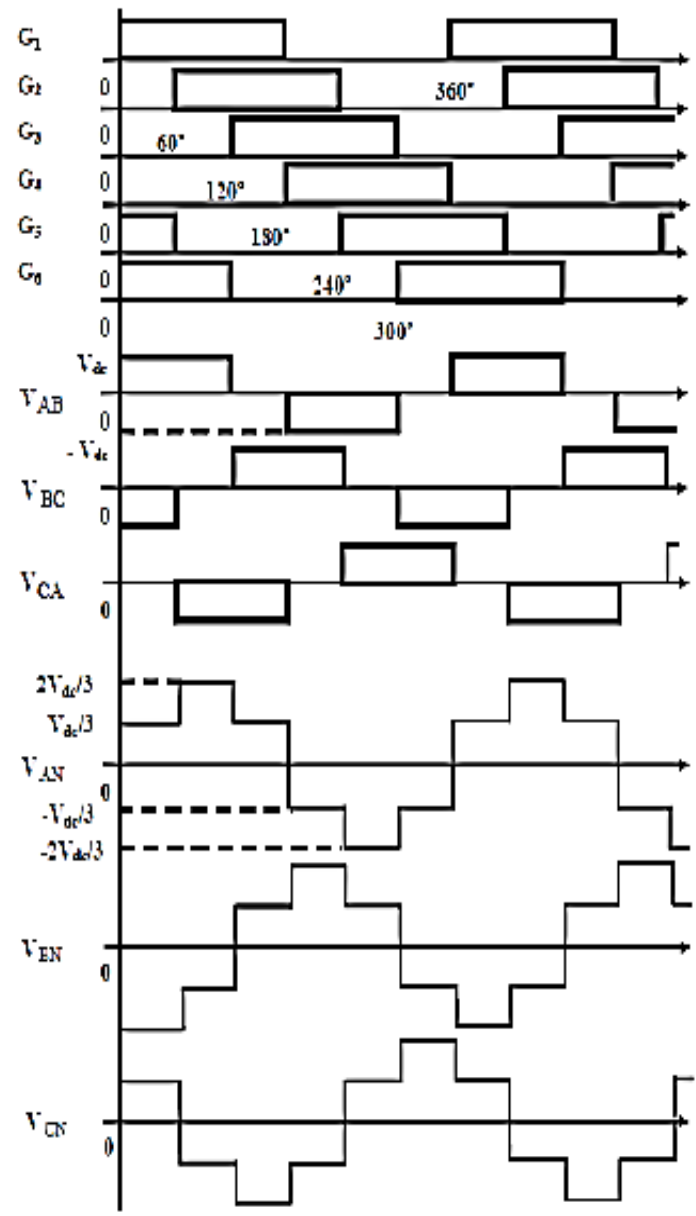

Fig 3 Gating sequence and voltage waveform.

\section{SIMULATION STUDIES}

Simulations are done using MATLAB/SIMULINK software tool for the analysis of speed control using voltage source inverter and performance of the system are observed with and without PI controllers in the system.

The following figure 4 shows the simulated diagram of the system.

Gating pulses for the switches are generated in such a manner that the output of the voltage source inverter must have 3 phase sinusoidal waves with $120^{\circ}$ phase shift between them.

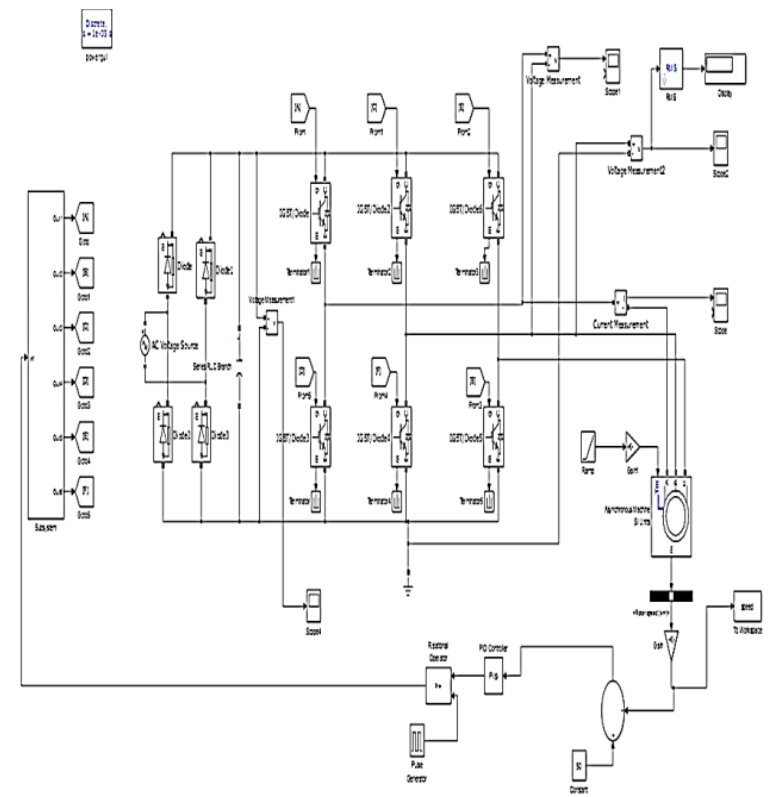

Fig 4 Simulated diagram of the system

In order to generate the gating pulses 3 pulse generators of $50 \mathrm{~Hz}$ frequency are taken with amplitude $10 \mathrm{~V}$ and these pulse generators are now compared with $1 \mathrm{kHz}$ pulse generator to get PWM pulses for the switches, By varying duty ratio of the pulse generators we can vary the inverter output voltage and hence speed can be controlled.

The following figure 5 shows the gating signal controls.

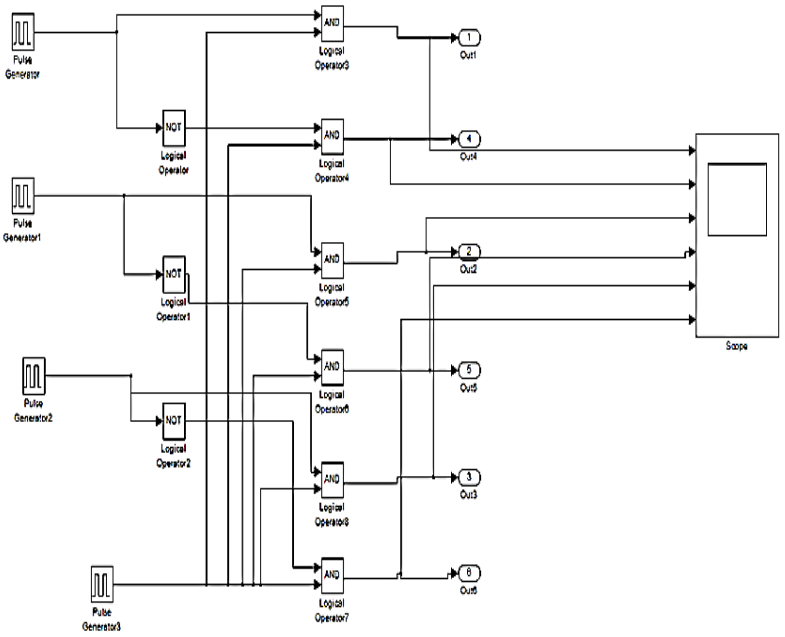

Fig 5 Gating signal control for VSI.

\section{SIMULATION RESULTS}

Simulation Results are obtained from MATLAB/ SIMULINK software tool. The results of line voltage, phase voltage, current in the line, capacitor voltage of Voltage Source Inverter are listed along with Speed, Torque results of Induction motor in the following figures. 
All the results are here obtained when PI controller is employed initially.

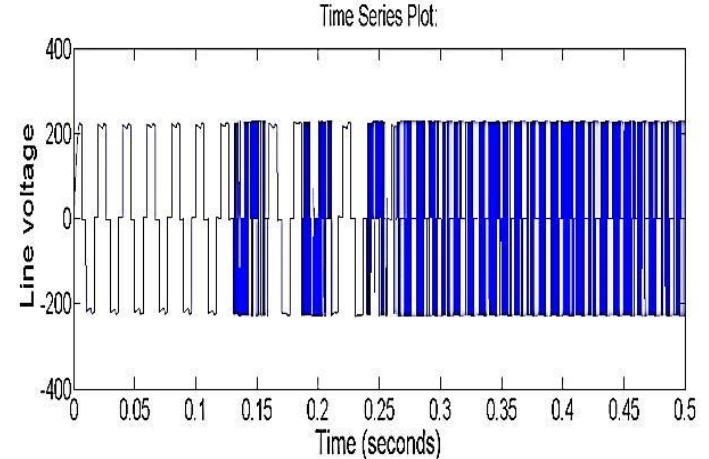

Fig 6.Line Voltage

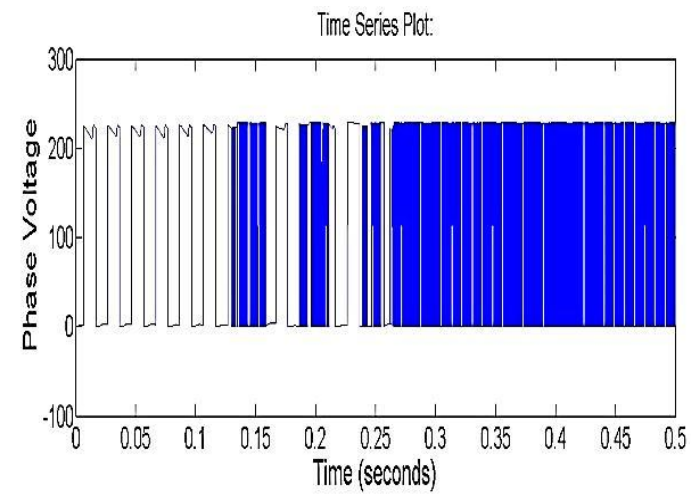

Fig 7. Phase Voltage.

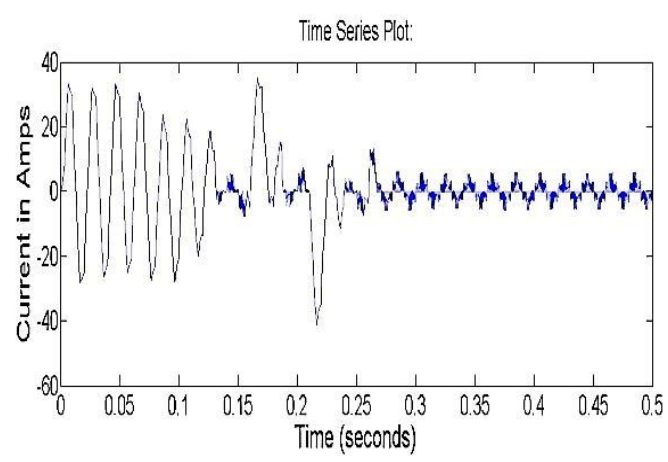

Fig 8.Current in R phase.

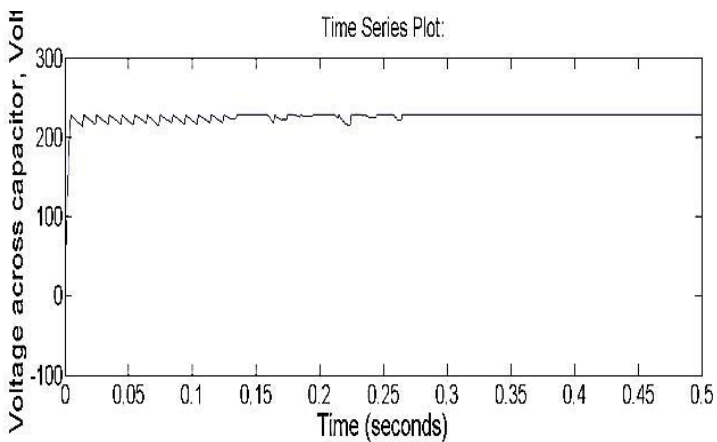

Fig 8.Voltage across capacitor.

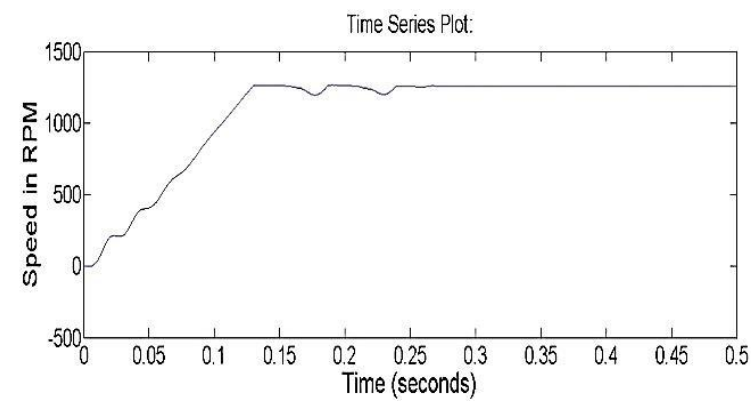

Fig 9. Speed in RPM.

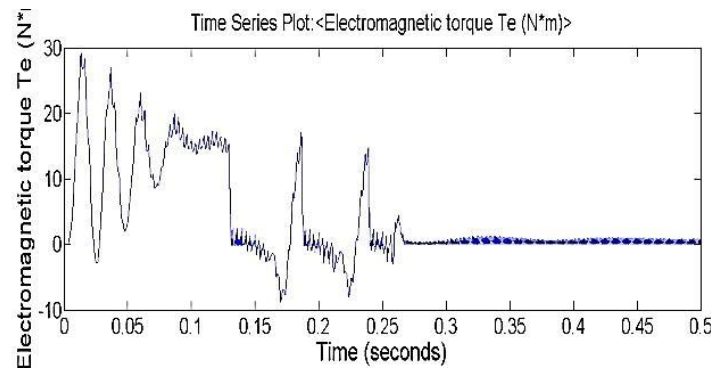

Fig 10. Torque in $\mathrm{N}^{*} \mathrm{~m}$

System performance can be compared when PI controller is deployed from the system for the same input parameters the system responds slower compared to when system is employed with PI controller and also system becomes less stable in the absence of PI controller.

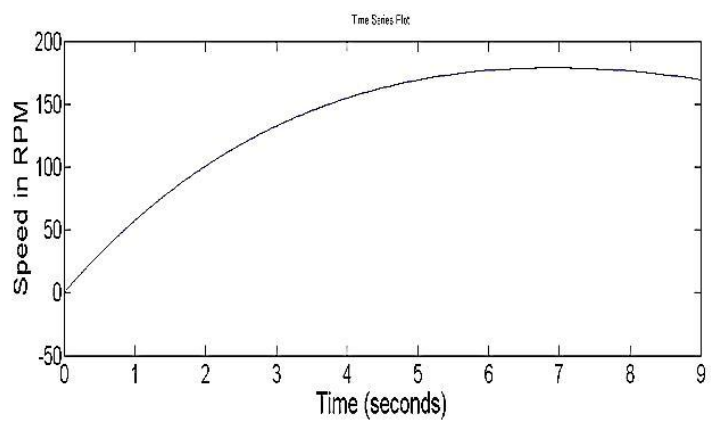

Fig 10. Speed when PI Controller is deployed.

\section{CONCLUSION}

Voltage source inverter fed induction motor drive is simulated. Voltage source inverter can be used to control the stator terminal voltage by controlling duty ratio of the switches. Hence stator terminal voltage is varied and results in speed variation of the motor. By properly controlling duty ratio desired speed range can be achieved in the motor.

\section{ACKNOWLDEMENT}

I sincerely express my gratitude to our Project Coordinator Mr. K. VASUDEVA SHETTIGAR Associate Professor 
Vol. 5, Special Issue 2, April 2017

and our HOD Dr. Nagesh Prabhu, Professor and Head, Department of E\&E, N.M.A.M Institute of Technology, Nitte for their timely scheduling of the project work and encouraging us to present papers.

\section{REFERENCES}

[1] F. W. Fuchs, "Some diagnosis methods for voltage source inverters in variable speed drives with induction machines-A survey," in Proc. 29th Annu. Conf. IEEE Ind. Electron. Soc., Roanoke, VA, pp. 1378- 1385, Nov. 2003

[2] R. A. Hanna and S. Prabhu, "Medium-voltage adjustable-speed drives users and manufactures experiences," IEEE Trans. Ind. Appl., vol. 33, no. 6, pp. 1407-1415, Nov./Dec. 1997.

[3] IJAREEIE paper, June 2015, Vol 4, issue 6, Voltage source inverter fed induction motor drive .

[4] IJEDR Paper, 2014, Volume 2, Issue 1, Speed Control of a Three Phase Induction Motor Using PWM Inverter .

[5] IJESIT , May 2015, Vol 4 Issue 3 ,New Pulse Width Modulation Technique for Three Phase Induction Motor Drive

[6] DUBEY, G.K, "Power semiconductor controlled drives" , Second edition, Prentice-Hall, New Jersey, 1989.

[7] BOSE, B.K, "Power electronics and AC drives", second edition, Prentice-Hall, New Jersey, 1986.

[8] Muhammed H Rahid,"Power electronics, circuits, devices and applications", Third edition, Pearson prentice hall, West florida, 2004.

[9] BOSE, B.K, "Technology trends in microcomputer control of electrical machines”, IEEE Trans. Ind. Electron., 35 (1), pp. 160177, Mar. 1988.

[10] P. S. Bimbhra," Power Electronics", Third edition, Khanna publishers, Delhi, 2003 